\title{
EMPOWERING ADOLESCENTS TO ENGAGE IN HEALTHY BEHAVIOURS THROUGH PEER LEADERSHIP TRAINING IN THE TOWNSHIPS OF CAPE TOWN
}

\section{Leena Eklund Karlsson, Mikael Andersson, and Josefine Johansson}

\begin{abstract}
This paper investigated peer educators' perceptions of their selfempowerment, learning, and experiences of being a peer educator within the Leadership South Programme (LSP) in Cape Town, South Africa. The data about the peer educators' perceptions was gathered through open-ended questionnaires and qualitative interviews and analysed through thematic content analysis. The results showed that peer educators' self-esteem, confidence, and motivation increased, as did their knowledge and skills related to communication, supporting, and motivating peers and clients. Additionally, the results showed that education based on trainee resources and strengths successfully promoted healthy behaviours and fostered health promotion among the adolescents living in the townships of Cape Town.
\end{abstract}

Keywords: empowerment, adolescents, peer education, training of trainers, health promotion, healthy behaviour, South Africa

Acknowledgements: This article is dedicated to the memory of Graham Vivian Phippen (1948-2012), who was the founder and leader of the LSP in Cape Town for 16 years. Graham continues to inspire us and we thank him for his support and assistance in implementing this study. We share the grief over his sudden death in 2012 with his relatives, colleagues, and friends.

We extend special thanks to the respondents who participated in this study. We are also grateful to the South African people who welcomed us so warmly and contributed to this study. We give special thanks to our guides and interpreters in South Africa for their time and knowledge, without which this research would not be possible. We also thank the Minor Field Study (MFS) scholarship funded by the Swedish International Development Cooperation Agency (SIDA) for supporting the data collection and field study in South Africa in 2011. 


\section{A note about author contributions:}

Mikael Andersson and Josefine Johansson were the primary researchers of the field study in South Africa. They collected and analysed the data. Leena Eklund Karlsson served as their supervisor across all phases of the study and also contributed as the main author of this article. All authors read and approved the final manuscript.

Leena Eklund Karlsson, Ph.D. (the corresponding author) is an Associate Professor at the Department of Public Health, University of Southern Denmark, Niels Bohrs Vej 9, 6700 Esbjerg, Denmark, and a Senior Lecturer at the Department of Nursing, Health and Culture, University West, Trollhättan, Sweden. E-mail: leklund@health.sdu.dk

Mikael Andersson is a Bachelor of Science, University West, Department of Nursing, Health and Culture. Kungsgatan 31, 46130 Trollhättan, Sweden. E-mail:

andersson.erik.mikael@gmail.com

Josefine Johansson is a Bachelor of Science, University West, Department of Nursing, Health and Culture. Address: Olof Gransgatan 30, 46141 Trollhättan, Sweden. E-mail: johansson.josefine85@gmail.com 
South Africa has more than 50 million inhabitants of diverse origins, cultures, languages, and religions. Approximately one-third of South Africa's population is younger than 15 years, and only $7.4 \%$ is older than 60 years. Although the population in South Africa grows annually, the upward trend has reached a plateau and the population might decrease in the future due to a heavy disease burden that includes the HIV/AIDS epidemic (Landguiden, 2012). The World Health Organization (2010) estimates that $17.8 \%$ of the population is HIVpositive. The high prevalence of HIV/AIDS is a major reason for South Africa's low life expectancy estimates of 54.9 years for males and 59.1 years for females (Statistics South Africa, 2011). According to Harrison, Newell, Imrie, and Hoddinott (2010), the HIV prevalence among 15- to 24-year-old South Africans is among the world's highest, even though these youth are knowledgeable about sexual health risks (Campbell \& MacPhail, 2002). Eaton, Flisher, and Aarø (2003) concluded that at least 50\% of young people are sexually active by the age of 16 years, and that between $50 \%$ and $60 \%$ of sexually active youth report never using condoms. MacPhail and Campbell (2001) have identified lack of perceived risk, peer norms, condom availability, adult attitudes to condoms and sex, gendered power relationships, and the economic context of adolescent sexuality as the main factors hindering condom use. Furthermore, studies of South African youth show that they are affected by sexual violence, forced sexual initiation, and rape (Andersson et al., 2004; Jewkes \& Abrahams, 2002; Jewkes, Penn-Kekana, \& Rose-Junius, 2005), which also increase the risk for HIV.

South Africa's battles with public health problems and a heavy disease burden are important areas of work for the vast number of domestic non-governmental organizations (NGOs) (Swilling \& Russel, 2002). The non-profit sector is a major force in South Africa. More than two million people are estimated to volunteer their time and expertise to NGOs annually (NGOPedia, 2009). The gap between the rich and the poor remains significant, with wide gaps between the education level and employment status of the white (European) minority and the non-white (African, multi-ethnic, and Asian) segments of the population (World Health Organization, 2009). Still, compared with other countries in the Sub-Saharan region, South Africa is relatively well developed. Although the country is riddled with great injustices and inequalities, it has the continent's strongest economy, primarily due to its rich natural resources (World Health Organization, 2009).

Poverty is a prevailing problem, especially in the areas known as "townships", which are located outside city centres. The townships in South Africa were created during the apartheid era (1948 to 1994) when the African, European, multi-ethnic, and Asian segments of the population were ordered to live separately by law (United Nations, 2012). These areas are characterised by high rates of unemployment, poverty, and a high density of people living in deficient environments in which housing, water, and sanitation are far below the standards of the richer areas of the city (Campbell \& MacPhail, 2002; Landguiden, 2012). Some residents live in houses, whereas some reside in shacks that are built of corrugated iron, wooden poles, and other available building materials. Still others live on the streets due to a lack of personal property. Schools are free of charge but are often underfunded and stressed with large classes and under-qualified teachers (Campbell \& MacPhail, 2002). 


\section{The Leadership South Programme}

The Leadership South Program (LSP) was founded in 1986 and is a registered NGO. Over the last 26 years, the organisation has developed and conducted a range of programmes and activities that have focused on such area as conflict resolution, reproductive health, lifeskill training, and peer education programmes. LSP training targets 13- to 18-year-old students, and the sessions are typically held in contracted schools after the scheduled school hours. The duration of the LSP's peer education programme is 3 years with an annual start-up for new peers, and approximately 1,500 peer educators have completed the programme. The LSP provides this education programme at 16 schools in the townships around Cape Town.

The LSP's overall mission is to enable and equip adolescents to train and educate youth leaders (i.e., "train the trainers") who will act as role models, providing guidance and support to their peers. An important goal for the LSP is to increase knowledge about HIV/AIDS in South Africa by educating healthy sexual behaviour among the youths (Leadership South Programme, 2010, 2011). To accomplish this goal, the LSP provides education programmes that are based on an approach that contributes to the adolescent's selfempowerment and strengthening of self-confidence. The LSP defines this approach as the "mental, physical, and spiritual coordination of self that equips each person to make a constructive difference in the development of their own lives and of those around them to uplift their communities and society in general" (Leadership South Programme, 2011, p. 1). The core of the peer education training is to strengthen youth leaders by sharing their experiences with their peers and others in their community, and in this way, to increase knowledge about, for example, the HIV/AIDS pandemic, risks for HIV, and how to make healthy decisions regarding sexual behaviour (Leadership South Programme, 2010, 2011). Throughout the entire education process, the participants exercise teaching, mentoring, and facilitation skills to support the participants to make a constructive difference in their own lives and the lives of those around them (e.g., learning to cope with group pressure and how to avoid HIV contamination and practice safe sex). The programme consists of the following components:

- $\quad$ Year 1, Junior. In the first year, the learner is provided with training in basic skills such as speaking in front of an audience, mediating and supporting behavioural change (e.g., from unsafe to safe sexual behaviour, avoiding and/or getting out of "gangsterism”, coping with alcohol and drug consumption problems, etc.), acting as a role model, employing strategies to overcome barriers, and using pedagogical methods for sharing experience and knowledge within a group.

- Year 2, Senior. In the second year, students continue to improve upon the skills that they acquired during the first year. This year focuses on the continuation of sharing of experiences, engaging the younger learners in the learning process, and disseminating information. A government-regulated, accredited curriculum and course plan steer Years 1 and 2.

- $\quad$ Year 3, Mentor. The government does not regulate the third year, and a syllabus is not mandatory. The peer educators learn to train the Junior and Senior students. The mentor serves as a facilitator for group discussions concerning subjects such as healthy sexual behaviour and behavioural change. A continued focus on sharing experiences and individual knowledge exists during this year. 
The training occurs in schools directly following the scheduled classes. Each township high school where the LSP was active is also co-operating with a primary school, where older students teach a group of younger students concerning such subjects as healthy sexual behaviours, everyday problem solving around conflicts with siblings or other family members, and bullying (Leadership South Programme, 2011). This approach is in line with Harrison et al.'s (2010) systematic review of HIV prevention interventions targeting youth in South Africa since 2000. That review concluded that such programmes should more strongly emphasise engaging schools in participatory learning. The peer educators arranged various sessions and theme days that became a part of their own technical training. During the holidays, the LSP arranged camps of up to 60 participants. At these camps, all individuals had responsibilities based on their interests and individual training.

\section{Empowerment}

Empowerment is a widely used concept in health promotion and public health (Laverack, 2006; Loukanova \& Bridges, 2008; Wallerstein, 2006; Wiggins, 2012). This term has been defined as both an outcome and a process through which individuals and communities gain greater control over health and the capacity to make or resist change (Tengland, 2007, 2008). Empowerment as an outcome refers to an individual's control over the determinants of his or her quality of life. Empowerment as a process refers to creating a professional relationship through which the individual or community takes control over the change process and determines both the goals and means of this process (Tengland, 2008). Through this process, individuals, organisations, and communities gain power and control over decisions and resources of concern to them (Rappaport, 1987; Zimmerman \& Rappaport, 1988; Oladipo, 2009). Prilletensky, Nelson, and Peirson (2001) added that the notion of power also includes opportunities for participation and self-determination as well as experiences of self-efficacy and competence. Empowerment is viewed as a multi-level construct that can be applied to individuals as well as organisations, communities, and social policies (Zimmerman \& Rappaport, 1988).

Zimmerman (1990) labelled the individual level of empowerment "Psychological Empowerment" (PE). He claimed that PE depends on the context and group of individuals included in the process. PE can be conceptualised to contain intrapersonal, interactional, and behavioural components (Zimmerman, Israel, Schulz, \& Checkoway, 1992). The intrapersonal component concerns thoughts about one's capacity to change or affect important political and social systems. This component includes motivation and perceived competence. The interactional component includes the development of problem-solving and decisionmaking skills for active engagement in the social environment. The behavioural component refers to the individual actions that one takes to influence his or her environment (Zimmerman et al., 1992), for example, by doing volunteer work for the LSP. Empowerment at the individual level is linked with that at the organisational and community levels through one's development of personal competence to act, and development of interpersonal, social, and political skills, and social support (Kieffer, 1984), as well as one's desire to influence and control the socio-political environment and willingness to take collective action (Zimmermann \& Rappaport, 1988; Wallerstein, 1992). Oladipo (2009) argued that PE is a prerequisite for achieving economic or community empowerment in general society. Oladipo (2009) further stated that when

people are psychologically empowered, there will be a change in attitude, cognition and behaviour, which most assuredly will lead to a positive change in value orientation, increased patriotic actions, ability to postpone gratification of one's 
desires, improved self-esteem, self-efficacy, and self-consciousness as well as better psychological well-being, which culminate in a peaceful and developing society. (p. 122)

Thus, empowerment must be investigated not only as an individual change but also as change in the social setting in which it appears (Wallerstein, 1992; Zimmerman, 1990).

Empowerment is most often gradually developed as an active, dialogical, educational development process that is inspired by the Freirian pedagogy for critical consciousness (Freire, 1993). Freire argued that a prerequisite for a positive behaviour change is the development of critical consciousness, which comprises the ability to critically reflect on the conditions that shape people's lives, the perceived capacity to effect social and political change, and collective action to change these conditions (Watts, Diemer, \& Voight, 2011). Freire (1993) emphasised the importance of critical consciousness for achieving social equality and justice. His pedagogy was intended to transform and empower vulnerable people from a position of oppression or helplessness to one of awareness and mastery of their own lives. Thus, the premise is that not only individual empowerment but also collective peer empowerment are important foundational principles for action.

\section{Peer Education and Empowerment}

According to the literature, interest is growing in participatory peer education as an HIV prevention strategy among young adult populations throughout the world (e.g., Ebreo, Feist-Price, Siewe, \& Zimmerman, 2002; Ochieng, 2003; Wegner, Flisher, Caldwell, Vergnani, \& Smith, 2008; Hatcher et al., 2011; Watts et al., 2011; Wiggins, 2012).

Empowerment through education for critical consciousness might be the key for the success of this peer education strategy (Campbell \& MacPhail, 2002; Campbell \& Cornish, 2010; Hatcher et al., 2011; MacPhail, 2006; Mohajer \& Earnest, 2009; Visser, 2005, 2007; Watts et al., 2011; Wiggins, 2012; Wilson, Minkler, Dasho, Wallerstein, \& Martin, 2008). Visser (2007) claimed that peer education is an appropriate HIV/AIDS prevention method among adolescents because youth may find it easier to discuss personal issues with peers than with adults, and they use a shared language. Drummond, Mizan, Brocx, and Wright (2011) added that the peer education approach might be successful in the area of sexual health topics that are generally considered "taboo" or overly sensitive to discuss.

Compared with traditional health education, peer education is an attempt to incorporate numerous individual opinions within a group process that consists of dialogue, argumentation between peers, and exchange and discussion of each other's experiences (Campbell \& MacPhail, 2002). Peer education provides a forum in which participants are able to assess their opinions about behavioural options with their peers. Peer education aims to create a negotiated collective identity that includes shared peer group norms, which then guide health behaviours rather than individual choices (Campbell \& MacPhail, 2002). According to Campbell and MacPhail, collective identity functions as a tool for social change. Peer education efforts should focus particularly on developing participants' critical consciousness of socially constructed gender-related norms that determine youth sexual behaviours (Campbell \& MacPhail, 2002; Selikow, Ahmed, Flisher, Mathews, \& Mukoma, 2009; Harrison et al., 2010). This recommendation is in line with a growing body of research that shows a clear correlation among African adolescents' gender-related socialisation, power relationships, and risky sexual behaviours (Varga, 2003).

Campbell and Mzaidume (2002) as well as Campbell (2004) argued that peer education should aim to create supportive social environments. This goal can be accomplished 
through: alliances between peer educators and influential groups (Campbell \& Mzaidume, 2002); collaborations between stakeholder groups at local, national, and international levels (Campbell, 2004); and partnerships between marginalised communities and support agencies such as NGOs (Nair \& Campbell, 2008). According to Campbell, Foulis, Maimane, and Sibiya (2005), health-supporting social environments encourage young people's social and political participation, facilitate their empowerment, and promote affirmative attitudes toward youth and their sexuality (see also, Campbell \& Cornish, 2010). Campbell, Gibbs, Maimane, Nair, and Sibiya (2009) suggested that projects that seek effective youth participation in HIV/AIDS leadership should first understand the psychosocial preconditions for such participation and how material, symbolic, and institutional environments either facilitate or hinder such participation.

The extant literature indicates that using peer educators is an appropriate approach for empowering young adult populations (e.g., Cornish \& Campbell, 2009; Ebreo et al., 2002; Ochieng, 2003; Wegner et al., 2008; Hatcher et al., 2011; Watts et al., 2011; Wiggins, 2012). However, evidence also shows the opposite effect (Ebreo et al., 2002) or little or no effect of peer education interventions compared with other types of interventions (Ochieng, 2003). Although many HIV/AIDS peer education programme evaluations exist and their results are documented, few studies have assessed the effect of these efforts on the peer educators themselves (Ebreo et al., 2002; Mohajer \& Earnest, 2009). The purpose of the current paper is to describe the peer educators' experience related to LSP training. The aims were to analyse the peer educators' perceived self-empowerment, to explore their perceptions of their own learning and development, and to describe their strategies for peer empowerment. The primary focus of this paper was individual empowerment because it is the link between, and prerequisite for, the other levels of empowerment. However, it was also important to know whether the empowered peer educators were successful in empowering further the youth who participated in the peer-led programs by supporting them (e.g., to change their sexual behaviours from unsafe to safe).

\section{The Present Investigation}

\section{Selection of the Study Approach}

A qualitative approach was selected for this study as it creates a condition that gives broader and richer descriptions by providing the participants with a possibility to express their thoughts freely, whereby interesting tracks can appear (Alvesson \& Deetz, 2000). Alvesson and Deetz point out the importance of getting close to the participants of the study but, still, keeping a certain distance in order to have an objective view of the situation.

Grounded Theory (GT), as described by Glaser and Strauss (1967) as well as Charmaz (2006), inspired the methodology of our study. Charmaz's (2006) version of GT was useful at the start of the analysis because it contains methodological guidelines and hands-on advice that can be used as a set of tools. Charmaz (2006) bases her interpretation of GT on the theoretical perspective of symbolic interactionism. She states that researchers are part of the world and that the collected data and every theory are constructions of the studied world rather than an exact copy of it. However, our initial aim was not to produce a complete theory grounded on the data as is required in the orthodox GT procedure (Glaser \& Strauss, 1967). Rather, we aimed to find certain themes or patterns across the data to characterise respondent experiences as peer leaders and to highlight their learning, participation, and empowerment. Thus, after the initial coding phase, the current analysis was similar to the thematic content analysis described by Braun and Clarke (2006). This analysis is considered to be suitable for examining experiences, meanings, and the realities of participants, as well as a range of 
ongoing discourses within society (Braun \& Clarke, 2006), for example, the discourse concerning gender roles, poverty, and their influence on sexual behaviours and HIV risk.

\section{Sampling and Participants}

Two former South African LSP mentors and facilitators with local knowledge, language skills, and contacts with the networks of peer educators, (i.e., gatekeepers) handpicked approximately 30 respondents they knew were available, interested, and who suited the purpose of this research. This subjective sampling technique is effective in reaching an elusive population (Denscombe, 2009) and is used in situations where the researcher already has some knowledge of the people or phenomena to be investigated. The researcher deliberately hand-picks some of these people as it is considered likely that these will have the most valuable data to illuminate the research question. The strategy used to locate respondents was also the most appropriate choice, given that we had a limited amount of time to conduct the study. Denscombe (2009) supported this type of respondent selection when he argued that a researcher should consider all resources, including assistance, transportation, time, and budget, when conducting a study. The gatekeepers served as cultural guides, interpreters, and advisers also during data collection. Thus, the gatekeepers were indispensable because legitimising the study would have been much more difficult to achieve in South Africa without their assistance.

The peer educator participants in this study included 13- to 18-year-old boys and girls who had completed the LSP training programme. The participants were fluent in English and Xhosa (their native tongue).

\section{Data Collection}

The data collection was conducted in two phases. First, open-ended questionnaires were administered. Then, qualitative interviews were conducted using an interview guide. This approach is an effective way to elicit data from respondents who prefer to express themselves in writing instead of speaking (Charmaz, 2006). We also considered that a method combination might provide a more complete description and/or explanation of the phenomena studied. This way, the results are more likely to respond to a wider range of issues and provide a more comprehensive account of what is being investigated (Denscombe, 2009).

A total of 27 questionnaires were distributed, and 26 were completed and returned (by 13 male and 13 female 13- to 18-year-olds). The open-ended questionnaire included questions concerning peer educators' experiences of leadership and participation (in the education programme and the community in general), motivation, and the development of personal skills. The questions were presented in a historical and visionary manner to facilitate respondents telling their leadership stories from the past to the present, their thoughts about their leadership roles in the future, and the desired support and training for their future peer leadership/educator roles. The questionnaire was based on Zimmerman and Rappaport (1988), who stated that a high level of involvement in community activities and organisations affects one's sense of empowerment. The data from the open-ended questionnaires were entered into a computer and reviewed several times before progressing to the second phase (the qualitative interviews). The objective of the additional data collection was to obtain greater detail regarding peer educators' subjective viewpoints, experiences, and perceptions concerning their development and performance.

Those who answered the open-ended questionnaires were asked about their interest in participating in the qualitative interview as a further chance to share views and experiences. 
Of the 26 respondents, 23 agreed to be interviewed. Six of these interviews were not analysed due to noise and interruptions, or failures to record the interviews such that they could not be fully transcribed and used as reliable data. The final dataset consisted of 17 complete interviews. The average interview was 35 minutes, resulting in approximately 10 hours of interview recordings. English was the primary language used during the interviews, although certain words required interpretation by the gatekeepers.

A written interview guide was used. It was constructed according to the same structure as the open-ended questionnaire including the same concepts. The concepts of motivation and participation were based on the article by Zimmerman and Rappaport (1988). Both concepts are considered important in the individual-focused empowerment theory. Leadership, education, and personal skills were also included in the interview guide. The interview guide was piloted with two respondents, which resulted in the addition of an item concerning context, experiences in the community setting, and community participation. The interviews were tape-recorded and transcribed verbatim.

\section{Thematic Content Analysis}

The thematic content analysis was conducted along the lines described by Braun and Clarke (2006). Two researchers carefully read the data and conducted the initial coding of words, lines, and incidents. During this initial phase, the researchers searched for actions, asked questions about what was occurring in the data, and concisely named the codes. In the second step of the analysis, the researchers examined larger segments of the text, and the most frequent initial codes were selected for additional coding when they captured a patterned meaning or theme that moved the analytic process forward with regard to the research questions. This process included inductively identifying emerging themes, coding them as appropriate, and discussing the codes and themes jointly with the research group to identify similarities and common attributes across them. The recurrent themes were then grouped to form subcategories and main categories. For example, one code regarding motivation was "having power to continue with training". As an increasing number of codes emerged from the data, codes with similar meanings were grouped for a higher level of abstraction. Finally, the codes were used to generate categories. As the coding proceeded, changes in the categories or the development of new categories occurred. These procedures were conducted by constantly comparing the data with the additional codes generated from the data. The aforementioned example code was ultimately categorised as "strengthening motivation".

\section{Ethical Considerations}

The participants completed and signed an informed consent and indemnity form prior to data collection. The form stated the research objectives, how the results would be used, and that no personal information or names would appear in the study. The signature of a parent or legal guardian was obtained for those participants under 18 years of age.

\section{Findings}

The results describe how peer educators who participated in the LSP experienced the training process and their own empowerment. These findings are presented within the framework of the study aims.

\section{Perceived Self-empowerment}

The results revealed that participation in the LSP strengthened the peer educators as follows: The respondents reported that their feelings of self-efficacy increased, their 
motivation to engage in programme activities became stronger, they learned to overcome their fears, and they felt healthier and happier. The respondents also explained that participation in the LSP was meaningful for them and the local community. The results indicated that the peer educators were empowered at the individual level. Many of the respondents stated that they were glad they had joined the LSP and that their participation in the programme contributed to their increased self-esteem. The data also showed that involvement in the LSP made the participants feel good and affected their lives in a positive manner:

Participation in the LSP made me stronger. When I was doing LSP, I was a bit shy, but the programme helped me to grow as a person, and now I know how to speak in front of people.

In the past, I had a problem: My self-esteem was low. But then I joined the leadership programme, and it helped me a lot. I gained a lot of knowledge on how to live my life and knowledge and experience with how to help people.

When I joined LSP, the peer education programme was dealing with HIV and leadership and dialogue. I took part in it, and it really changed me because before I joined LSP, I couldn't stand in front of people; I was not able to say what I wanted to say. But after I joined LSP, I changed through their teaching.

The quotes above indicate that the LSP helped the peer educators overcome such fears as speaking and presenting in front of a group. The respondents reported that the training improved their self-confidence. Furthermore, the respondents stated that their interest in leadership and the other topics that they discussed during the programme (e.g., HIV/AIDS prevention, femininity/masculinity, psychology of health behaviours, and gender roles) provided them with new knowledge, which inspired them to continue with their training:

Every session motivated me and changed my life in so many different ways. I used to think negative thoughts and say to myself, "I'm weak and helpless". But now I know that I can change. I am grateful.

I feel good. I have changed from what I was. Now, I am someone who can act as a role model for others.

Leading programme has taught me a lot, and I want to proceed with learning more.

You, as the peer educator, assist with decision-making, and let the person choose from the options that you have given. Then, later on, that person can make his or her decisions him or herself. I want to continue to do this.

Being a leader has made me realise how precious life is. Since I've been in the leading phase, I have learned a lot about life and the challenges that it brings/has for us. I have met so many people with similar stories like mine: abuse, parents who drink, and other problems that we as youth face. So, being a leader boosts my self-image and self-esteem. 


\section{Perceptions of Learning and Development as a Peer Educator}

Participation in the LSP increased learning and self-development. The respondents reported that they gained improved communication and problem-solving skills, learned how to behave in a healthier manner (e.g., improved knowledge concerning healthy choices in different situations), acquired leadership skills, gained increased self-consciousness, and gained knowledge about healthy sexual behaviours. The respondents explained that their improved knowledge and skills were crucial for serving as role models for other adolescents. The most common skills that the peer educators considered to be important were those related to communication, support, and facilitation. The respondents also viewed the problem-solving methods as useful. They stated that their problem-solving strategies included consultation with the person having a problem, providing information regarding relevant issues of concern, and coaching him or her to find solutions.

They teach me, like, more about how to be a leader for others and how to communicate and keep myself up to date. Now, like, I can even advise others when they have problems because of Leadership South.

Every session motivated me and changed my life in so many different ways. I used to think negative thoughts and say to myself, "I'm weak". But now I know that I'm great. I experience that you can live life without having sex, and you can enjoy your life to the fullest if you are keeping yourself busy always.

They gave us training on how to solve a problem or how to counsel someone. They gave us methods on how to solve a problem, and I am still using those methods.

Another important lesson that the respondents learned was how to treat people equally by respecting all people and their values rather than judging them. Their involvement in the LSP broadened respondents' ways of thinking and their understanding of others' interests and views of life. The participants also expressed that they gained the courage to share their own experiences and stories to support others. Many respondents stated that encouraging others increased their understanding of themselves (i.e., self-consciousness). The LSP taught the peer educators how to simultaneously handle different situations and support their peers. Caring for others resulted in strengthened beliefs about their own abilities. This situation was a "win-win" for the peer educators because they were empowered as individuals by supporting and consulting with others:

Peer education and peer counselling have given me a broader way of thinking, listening abilities, and skills for providing to and receiving information from others. From now on, I can guarantee that I can offer good leadership.

It feels good because when you teach children, you also learn yourself. So, it also teaches back to you.

I'll make sure that I involve myself with different people so that I will be able to understand them, but not end up judging them... because, like, when people don't know you, they start to judge you. So, like, I try to put myself in a level that they will understand me and I will understand them. 
In addition to behavioural skills, the LSP taught peer life skills, with a major focus on HIV/AIDS issues. Many of the peer educators were aware of the severity of the AIDS situation in Africa and reported being engaged in helping to disseminate and inform other peers regarding healthy sexual behaviours. The respondents mentioned that they had learned how to manage sex and HIV/AIDS as a part of their life skills training. They also emphasised the importance of avoiding sex before marriage. Thus, the respondents challenged the prevailing socially derived norms and peer pressures regarding sexual behaviour. According to Selikow et al. (2009), abstinence from sex and the delay of sexual debut are typically undermined by adolescents' strong need to belong to a social group because sexual activity gives adolescents access to a group. The results also indicated that the peer educators were successful in advocating and integrating new norms regarding sexual debut into their new collective identity (Campbell \& MacPhail, 2002), which can further serve as a basis for solidarity and collective action (Watts et al., 2011).

All respondents mentioned that the sharing of information was the most crucial aspect of HIV/AIDS prevention. The peer educators showed great interest and sufficient knowledge regarding the HIV/AIDS issue. Their improved cognitive and social skills boosted their ability to understand the information and critically use it in their health promotion work:

If I get something from LSP, like, knowledge about HIV, yes, I do share this with my class and conduct a debate about it.

I like to know everything, like, especially about HIV. I wanted to be mostly involved in HIV, to tell people how not to get infected by HIV because I've seen how South Africa struggles with HIV. I want to make a change. This is what I tell myself when I go to this organisation, like, I tell myself that I want to make a change.

I've been part of the LSP, and I've been teaching my peers about HIV and AIDS and telling them, for example, that sex is not a right thing to do until you get married.

\section{Experiences with the Process of Empowering Others}

One of the aims of the LSP's work is to train peer educators to share experiences and transfer skills and knowledge to others, with the overall mission of improving the community. The trained peer educators are, in turn, expected to facilitate and enable their peers to strive toward empowerment (Leadership South Programme, 2011). According to the results, the informants pursued their mission with great seriousness. They mentioned that when serving as a peer educator, listening, advocating good choices, and supporting and advising others were the most important strategies:

It is all about helping your peers to learn from other people's experiences and ideas, sharing information with them and ensuring that they get the relevant information and that they are also sharing information with others.

The nicest thing is that you never see me sitting alone. I always try to sit in groups with other people. I always try to involve myself in many things, so I share my skills, okay. I do most talking, but I don't just talk. The talk is about a lot of things, things that other people are talking about.

To inspire and affect others, the peer educators reported that they purposefully acted in a positive and respectful manner so that others could follow their example. Due to the LSP's 
training regarding how to support and encourage others, the peer educators felt confident in their mission and combined this feeling with a sense of power. Many peer educators stated that they motivated others in the same way that they were motivated by their family, friends, and teachers, or by sharing their own mistakes and experiences.

I think motivation is like giving someone the power to do what they would like to do. Not exactly giving them the power, but making them feel confident about what they want to do and supporting them with their ideas.

Well, it becomes hard if I don't know the person but to motivate others, I always try to motivate a person. Even if I don't know what to say, like, even if that person doesn't know where to go or is feeling down or something, I always try to convince him: "Now, It will be okay!" But sometimes I feel like, "Okay, what am I saying to this person? Did I scare him?” But then I usually come around. I don't like talking negatively, so I always try to bring the positive side to something.

I like to motivate people because I don't want to see them go the wrong way like I did. That's why I motivate people to go, to do right things. I don't want them to do the wrong that I've done.

According to the data, the LSP influenced and changed many participants' lives. By joining the programme, the informants acquired a broader understanding of sexual behaviours, leadership, and peer education as well as a more accepting manner of thinking with regard to other people's ideas, norms, and behaviours. Certain participants experienced a change in their views and preconceptions about others. Some participants stated that the LSP was a turning point in their lives. Regardless of the participant background (i.e., poor, middleor upper-class families), the LSP was perceived as an important mechanism of support. The participants explained that the support from the LSP enabled them to use their peer educator skills in other situations:

I've been, like, doing bad things and want life to change me. I think the programme is about how to change and about learning how to be yourself.

I feel good because I help other people to help themselves.

I used to hang out with friends that drink alcohol and use drugs, but now I... only now when I came back from the sessions I participated, I just can tell them that "guys, you need to change because this is not the way to live life; you can really have so much better lives than this, 'cause now you don't have the choice like doing drugs and all that kind. You know, it's not like going to take you somewhere in life, it's just gonna, like, ruin your life and... you know, you end up being nothing and useless to people..."

I was not doing good things. So, I wasted my whole two years doing that thing and then I realised that at the end of the day, I will be alone.... I feel like I don't know what I'm doing when I'm in "gangsterism", just because when you are a gangster, you don't tell yourself, "Now, I'm a gangster”. Someone forces you to be a gangster. 
According to the respondents, many of their classmates were behind in their studies and attended grade levels with younger students:

I was hanging around, not studying, so I became involved in "gangsterism" for two years. I am actually supposed to be in Grade 11.

The respondents explained that many adolescents in the townships dropped out of school because they had no relationships with their fathers. They often had to work in the rural areas around Cape Town. Their fathers left them with the major responsibility of taking care of their younger siblings.

I do have some responsibilities at home, yeah, after school I have to do the washing first, and then I cook for them (my siblings).

Along with poor schools with underqualified teachers, the respondents indicated that a shortage of school meals and too many students in each class were common. These factors were perceived as barriers to their studies. The respondents expressed that participation in the LSP with other adolescents who were in similar situations provided them with support to attend school and motivated them to take control over their own education.

\section{Discussion}

The current findings showed that the LSP peer education program improved both the motivation and competence of the participating peer educators. These educators experienced increased self-esteem, learned how to overcome their fears, developed the competence to act respectfully, and found an increased meaningfulness in their peer educator role. These results confirm many of the advantages of peer leadership through peer education as described by Ocheing (2003). However, residence in a township environment highly marked by poverty, injustice, and inequalities (e.g., Campbell \& MacPhail, 2002; Campbell, Gibbs, et al., 2009) as well as a poor school environment and a lack of parental support might have negative effects on adolescent perceptions of their own capacities and beliefs that community change is possible. Due to these structural and contextual barriers, some respondents doubted their longterm capabilities to organise and implement the course of action required of peer leaders. Although participation in the LSP positively affected the peer educators' feelings of selfefficacy and self-esteem, it seems that an intervention longer than 3 years would be necessary in order to strengthen their belief in community change, which according to the results were shown to be vague. This finding is in line with Campbell and MacPhail's (2002) call for longterm peer education activities that build adolescents' confidence and ability to take control over their life situations. Thus, time and practice are crucial for developing empowerment (Kieffer, 1984).

The data revealed that informants believe that because of their participation in the LSP, they had developed improved communication skills with their peers and community members, better leadership and problem-solving abilities, and increased knowledge about HIV and healthy sexual behaviour. The LSP succeeded in developing participant confidence with regard to making healthy decisions and the belief that these choices lead to positive outcomes. It seems that the participants had gained a feeling of being able to better control their environments and personal circumstances (e.g., in dealing with group pressure), which according to Koelen and Lindström (2005) increases the likelihood of making healthy choices. 
Our study indicates that the use of peer educators was an effective way to build the competencies that are useful in leading peers and generate sustainable attitudes supporting healthy sexual behaviour. This finding corroborates Ochieng's (2003) conclusion that peer leadership can change attitudes toward HIV/AIDS and other health-related matters. Thus, peer education strengthened the interactional component (Zimmerman et al., 1992) of psychological empowerment.

The behavioural component refers to an individual's participation in organisations and activities to influence his or her environment (Zimmerman et al., 1992; Oladipo, 2009). Our results demonstrated that peer educators are willing to commit to the work of the LSP to improve their community. Participation in the activities of this NGO improved adolescents' psychological empowerment. This finding emphasises the importance of the work conducted by NGOs and other organisations similar to the LSP (Ochieng, 2003). NGOs provide the support environment required for a successful empowerment process where alliances and partnerships between peer educators and influential community agencies (Campbell, 2004; Campbell \& Mzaidume, 2002; Nair \& Campbell, 2008) can be established. NGOs can also provide spaces where peer educators can fulfil their desires to belong to a group (Selikow et al., 2009) and simultaneously learn the positive norms that are essential when serving as peer role models.

The LSP training program enabled participants to assimilate knowledge and skills for a more reflective and investigative approach to their environments. According to Freire (1993), this knowledge is a prerequisite for positive behavioural change. The training aims to create conditions for the development of the critical consciousness of youth through activities such as involvement in preparing syllabi, exercises, discussions, and training/lectures. Participants' process of empowering their peers most often took the form of sharing experiences and thoughts within a group. The literature (Kieffer, 1984) claims that this behaviour is the essence of the empowerment learning process. We believe that the peer educators reached the psychological level of empowerment (as described above) and then used it as a resource to empower others. In addition, when a student chose to participate in the LSP, he or she had already reached the first level of self-empowerment: the awareness of a need to change. Kieffer (1984) called this level the era of entry. This first level of empowerment is followed by the sharing of experiences with other like-minded peers. Using Kieffer's (1984) terms, we interpreted this activity as the advanced era of empowerment, which is characterised by mentoring relationships, increased critical consciousness of social and political relationships, improved strategic and leadership skills, and a matured ability for critical thinking. The data also indicated that the peer educators were committed to applying their new abilities in everyday situations.

\section{Methodological Considerations}

The various data coding steps were complicated, and developing an understanding of the informants' language and statements was time consuming. However, we ensured the validity of our interpretation by continuously discussing our interpretation of the data including the coding procedures, the selection of themes, and category creation - and our results with the research group.

The researchers found that it was difficult to remain open-minded and avoid preconceived thoughts (i.e., bracketing; Charmaz, 2006); this limitation might have affected the trustworthiness of this research. Although we attempted to remain neutral, it is likely that our underlying values partially affected the study. According to Charmaz (2006), the 
researcher always represents the field in which he or she is trained; therefore, the results are always constructed in concert with the respondent data and the prior knowledge of the researcher.

\section{Conclusions}

This study examined whether the training provided by the LSP increased peer educators' perceived positive feelings of empowerment. Many HIV/AIDS peer education programmes have been used to deliver information and training to adolescents; however, few researchers have studied the effect of these programmes on peer educators themselves (Ebero et al., 2002; Ochieng, 2003). The current study helps us to understand the effects of one such programme on peer educators and indicates the need for additional research on programmes such as the LSP. The results indicated that peer educators' empowerment through the intervention increased their self-esteem and autonomy, their capacity for critical thinking, and their perceived self-efficacy concerning healthy choices. The study also showed that the LSP had positive health effects on the peer educators and their peers. These effects might, in turn, positively affect community development, thereby promoting the health and well-being of the local community.

The youths who participated in the LSP gained knowledge and tools for coping with a variety of situations, such as conflict management, how to manage peer pressure, and how to say no to sex. In many respects, the environment where these youth live is burdened with negative influences (e.g., poverty, unemployment, crime, drugs, poor schools, and a lack of leisure time activities). However, the LSP training resulted in opportunities for a better future. Nearly all respondents had visions of obtaining good-paying jobs, such as those held by social workers and politicians, to contribute to a better society. Many respondents felt that they had gained the power and ability to influence and change their environments through the LSP. However, the practice, support, and guidance provided by the intervention/training organisers over several years were crucial for achieving sustainable results (e.g., training a peer educator who is committed to his or her role model tasks even after completing the formal training). Our conclusion is that education based on peer trainee resources and strengths successfully promotes healthy behaviours and fosters health promotion among the adolescents living in the township areas. However, the sustainability of these results remains unclear because its verification would need a long-term follow-up assessment. 


\section{References}

Alvesson, M., \& Deetz, S. (2000). Kritisk samhällsvetenskaplig metod [Critical social science methodology]. Lund, Sweden: Studentlitteratur.

Andersson, N., Ho-Foster, A., Matthis, J., Marokoane, N., Mashiane, V., Mhatre, S., et al. (2004). National cross sectional study of views on sexual violence and risk of HIV infection and AIDS among South African school pupils. British Medical Journal, 329(7472), 952-954. http://dx.doi.org/10.1136/bmj.38226.617454.7c

Braun, V., \& Clarke, V. (2006). Using thematic analysis in psychology. Qualitative Research in Psychology, 3(2), 77-101. http://dx.doi.org/10.1191/1478088706qp063oa

Campbell, C. (2004). Creating environments that support peer education: Experiences from HIV/AIDS-prevention in South Africa. Health Education, 104(4), 197-200. http://dx.doi.org/10.1108/09654280410546682

Campbell, C., \& Cornish, F. (2010). Towards a "fourth generation" of approaches to HIV/AIDS management: Creating contexts for effective community mobilisation. AIDS Care, 22(S2), 1569-1579. http://dx.doi.org/10.1080/09540121.2010.525812

Campbell, C., Foulis, C., Maimane, S., \& Sibiya, Z. (2005). The impact of social environments on the effectiveness of youth HIV prevention: A South African case study. Aids Care, 17(4), 471-478. http://dx.doi.org/10.1080/09540120412331319705

Campbell, C., Gibbs, A., Maimane, S., Nair, Y., \& Sibiya, Z. (2009). Youth participation in the fight against AIDS in South Africa: From policy to practice. Journal of Youth Studies, 12(1), 93-109. http://dx.doi.org/10.1080/13676260802345757

Campbell, C., \& MacPhail, C. (2002). Peer education, gender and the development of critical consciousness: Participatory HIV prevention by South African youth. Social Science \& Medicine, 55(2), 331-345. http://dx.doi.org/10.1016/s0277-9536(01)00289-1

Campbell, C., \& Mzaidume, Y. (2002). How can HIV be prevented in South Africa? A social perspective. British Medical Journal, 324(7331), 229-232. http://dx.doi.org/10.1136/bmj.324.7331.229

Charmaz, K. (2006). Constructing grounded theory: A practical guide through qualitative analysis. London: SAGE Publications Inc.

Cornish, F., \& Campbell, C. (2009). The social conditions for successful peer education: A comparison of two HIV prevention programs run by sex workers in India and South Africa. American Journal of Community Psychology, 44(1-2), 123-135. http://dx.doi.org/10.1007/s10464-009-9254-8

Denscombe, M. (2009). Forskningshandboken: För småskaliga forskningsprojekt inom samhällsvetenskaperna [Research guide: For small-scale research projects in the social sciences]. Lund, Sweden: Studentlitteratur.

Drummond, P. D., Mizan, A., Brocx, K., \& Wright, B. (2011). Using peer education to increase sexual health knowledge among West African refugees in Western Australia.

Health Care for Women International, 32(3), 190-205. http://dx.doi.org/10.1080/07399332.2010.529215

Eaton, L., Flisher, A. J., \& Aarø, L. E. (2003). Unsafe sexual behaviour in South African youth. Social Science \& Medicine, 56(1), 149-165. http://dx.doi.org/10.1016/s0277-9536(02)00017-5 
Ebreo, A., Feist-Price, S., Siewe, Y., \& Zimmerman, R. S. (2002). Effects of peer education on the peer educators in a school-based HIV prevention program: Where should peer education research go from here? Health Education \& Behavior, 29(4), 411-423. http://dx.doi.org/10.1177/109019810202900402

Freire, P. (1993). Education for critical consciousness. New York: Continuum.

Glaser, B. G., \& Strauss, A. L. (1967). The discovery of grounded theory: Strategies for qualitative research. New York: Aldine de Gruyter:.

Harrison, A., Newell, M. L., Imrie, J., \& Hoddinott, G. (2010). HIV prevention for South African youth: Which interventions work? A systematic review of current evidence. BMC Public Health, 10(1), 102. doi: 10.1186/1471-2458-10-102

Hatcher, A., de Wet, J., Bonell, P. C., Strange, V., Phetla, G., Proynk, P. M., et al. (2011). Promoting critical consciousness and social mobilization in HIV/AIDS programmes: Lessons and curricular tools from a South African intervention. Health Education Research, 26(3), 542-555. http://dx.doi.org/10.1093/her/cyq057

Jewkes, R., \& Abrahams, N. (2002). The epidemiology of rape and sexual coercion in South Africa: An overview. Social Science \& Medicine, 55(7), 1231-1244. http://dx.doi.org/10.1016/s0277-9536(01)00242-8

Jewkes, R., Penn-Kekana, L., \& Rose-Junius, H. (2005). “If they rape me, I can’t blame them": Reflections on gender in the social context of child rape in South Africa and Namibia. Social Science \& Medicine, 61(8), 1809-1820. http://dx.doi.org/10.1016/j.socscimed.2005.03.022

Kieffer, C. H. (1984). Citizen empowerment: A developmental perspective. Prevention in Human Services, 3(2-3), 9-36. http://dx.doi.org/10.1300/j293v03n02_03

Koelen, M., \& Lindström, B. (2005). Making healthy choices easy choices: The role of empowerment. European Journal of Clinical Nutrition, 59, S10-S16. http://dx.doi.org/10.1038/sj.ejcn.1602168

Landguiden. (2012). / Länder / omrăden / Sydafrika [Country Guide. (2012). Countries / regions / South Africa]. (Last updated 2012-01-20). [Electronic]. Stockholm, Sweden: Utrikespolitiska Institutet [Institute of International Affairs]. Retrieved January 21, 2013, from http://www.landguiden.se/Lander/Afrika/Sydafrika?p=1

Laverack, G. (2006). Improving health outcomes through community empowerment: A review of the literature. Journal of Health, Population and Nutrition (JHPN), 24(1), $113-120$.

Loukanova, S. N., \& Bridges, J. F. P. (2008). Empowerment in medicine: An analysis of publication trends 1980-2005. Central European Journal of Medicine, 3(1), 105-110. http://dx.doi.org/10.2478/s11536-007-0066-7

Leadership South Programme (LSP). (2010). The leadership south programme: Annual report, 2009-2010. Cape Town, South Africa: Author.

Leadership South Programme (LSP). (2011). The leadership south programme: Annual report, 2010-2011. Cape Town, South Africa: Author.

MacPhail, C. (2006). Youth-driven HIV prevention programmes in South Africa: Social capital, empowerment and conscientization. Social Dynamics, 32(2), 170-196. http://dx.doi.org/10.1080/02533950608628731 
MacPhail, C., \& Campbell, C. (2001). "I think condoms are good but, aai, I hate those things": Condom use among adolescents and young people in a Southern African township. Social Science \& Medicine, 52(11), 1613-1627. http://dx.doi.org/10.1016/s0277-9536(00)00272-0

Mohajer, N., \& Earnest, J. (2009). Youth empowerment for the most vulnerable: A model based on the pedagogy of Freire and experiences in the field. Health Education, 109(5), 424-438. http://dx.doi.org/10.1108/09654280910984834

Nair, Y., \& Campbell, C. (2008). Building partnerships to support community-led HIV/AIDS management: A case study from rural South Africa. African Journal of AIDS Research, 7(1), 45-53. http://dx.doi.org/10.2989/ajar.2008.7.1.6.434

NGOPedia. (2009). What is an NGO / NGOs in South Africa (last updated 2009-10-30). [Electronic]. Somerset West, South Africa: Author. Retrieved November 21, 2013, from http://wiki.ngoconnectafrica.org/wiki/What_is_an_NGO\%3F

Ochieng, B. M. N. (2003). Adolescent health promotion: The value of being a peer leader in a health education/ promotion peer education programme. Health Education Journal, 62(1), 61-72. http://dx.doi.org/10.1177/001789690306200107

Oladipo, S. E. (2009). Psychological empowerment and development. Edo Journal of Counselling, 2(1), 118-126. http://dx.doi.org/10.4314/ejc.v2i1.52661

Prilleltensky, I., Nelson, G., \& Peirson, L. (2001). The role of power and control in children's lives: An ecological analysis of pathways toward wellness, resilience and problems. Journal of Community and Applied Social Psychology, 11(2), 143-158. http://dx.doi.org/10.1002/casp.616

Rappaport, J. (1987). Terms of empowerment/exemplars of prevention. Toward a theory for community psychology. American Journal of Community Psychology, 15(2), 121148. http:/dx.doi.org/10.1007/bf00919275

Selikow, T. A., Ahmed, N., Flisher, A. J., Mathews, C., \& Mukoma, W. (2009). I am not "umqwayito": A qualitative study of peer pressure and sexual risk behaviour among young adolescents in Cape Town, South Africa. Scandinavian Journal of Public Health, 37(2 suppl), 107-112. http://dx.doi.org/10.1177/1403494809103903

Statistics South Africa. (2011). Mid-year population estimates 2011 [Electronic]. Pretoria, South Africa: Author. Retrieved November 21, 2013, from http://www.statssa.gov.za/publications/P0302/P03022011.pdf

Swilling, M., \& Russell, B. (2002). The size and scope of the non-profit sector in South Africa. Durban, South Africa: Centre for Civil Society, University of Natal.

Tengland, P. A. (2007). Empowerment: A goal or a means for health promotion? Medicine, Health Care and Philosophy, 10(2), 197-207. http://dx.doi.org/10.1007/s1 1019-006-9027-1

Tengland, P. A. (2008). Empowerment: A conceptual discussion. Health Care Analysis, 16(2), 77-96. http://dx.doi.org/10.1007/s10728-007-0067-3

United Nations. (2012). [Electronic]. United Nations cyber school bus. New York: Author Retrieved November 21, 2013, from http://www.un.org/Pubs/CyberSchoolBus/discrim/race_b_ita_print.asp 
UNAIDS, Joint United Nations Programme on HIV/AIDS. (1997). Best practice collection. Impact of HIV and sexual health education on the sexual behaviour of young people: A review update. [Electronic]. Geneva: Author. Retrieved November 21, 2013, from http://data.unaids.org/publications/IRC-pub01/jc010-impactyoungpeople_en.pdf

Varga, C. A. (2003). How gender roles influence sexual and reproductive health among South African adolescents. Studies in Family Planning, 34(3), 160-172. http://dx.doi.org/10.1111/j.1728-4465.2003.00160.x

Visser, M. J. (2005). Life skills training as HIV/AIDS preventive strategy in secondary schools: Evaluation of a large-scale implementation process. SAHARA-J: Journal of Social Aspects of HIV/AIDS, 2(1), 203-216. http://d.doi.org/10.1080/17290376.2005.9724843

Visser, M. J. (2007). HIV/AIDS prevention through peer education and support in secondary schools in South Africa. Journal of Social Aspects of HIV/AIDS, 4(3), 678-694. http://dx.doi.org/10.1080/17290376.2007.9724891

Wallerstein, N. (1992). Powerlessness, empowerment and health: Implications for health promotion programs. American Journal of Health Promotion, 6(3), 197-205. http://dx.doi.org/10.4278/0890-1171-6.3.197

Wallerstein, N. (2006). What is the evidence on effectiveness of empowerment to improve health? (Report). Copenhagen: WHO Regional Office for Europe (Health Evidence Network). Retrieved November 21, 2013, from http://www.euro.who.int/_data/assets/pdf_file/0010/74656/E88086.pdf

Watts, R. J., Diemer, M. A., \& Voight, A. M. (2011). Critical consciousness: Current status and future directions. New Directions for Child and Adolescent Development, Winter 2011(134), 43-57. doi: 10.1002/cd.310

Wegner, L., Flisher, A. J., Caldwell, L. L., Vergnani, T., \& Smith, E. A. (2008). Healthwise South Africa: Cultural adaptation of a school-based risk prevention programme.

Health Education Research, 23(6), 1085-1096. http://dx.doi.org/10.1093/her/cym064

World Health Organization (WHO). (2009). WHO country cooperation strategy 2008-2013: South Africa [Electronic]. Brazzaville, Congo: Regional Office for Africa. Retrieved November 21, 2013, from http://www.who.int/countryfocus/cooperation_strategy/ccs_zaf_en.pdf

World Health Organization (WHO). (2010). Countries/ South Africa/ country health profile (last updated 2012-05). [Electronic]. Pretoria, South Africa: WHO. Retrieved November 21, 2013, from http://www.who.int/gho/countries/zaf.pdf

Wiggins, N. (2012). Popular education for health promotion and community empowerment: A review of the literature. Health Promotion International, 27(3), 356-371. http://dx.doi.org/10.1093/heapro/dar046

Wilson, N., Minkler, M., Dasho, S., Wallerstein, N., \& Martin, A. C. (2008). Getting to social action: The Youth Empowerment Strategies (YES!) project. Health Promotion Practice, 9(4), 395-403. http://dx.doi.org/10.1177/1524839906289072

Zimmerman, M. A. (1990). Taking aim on empowerment research: On the distinction between psychological and individual conceptions. American Journal of Community Psychology, 18(1), 169-177. http://dx.doi.org/10.1007/bf00922695 
International Journal of Child, Youth and Family Studies (2014) 5(2): 258-278

Zimmerman, M. A., Israel, B. A., Schulz, A., \& Checkoway, B. (1992). Further explorations in empowerment theory: An empirical analysis of psychological empowerment.

American Journal of Community Psychology, 20(6), 707-727. http://dx.doi.org/10.1007/bf00942234

Zimmerman, M. A., \& Rappaport, J. (1988). Citizen participation, perceived control and psychological empowerment. American Journal of Community Psychology, 16(5), 725-750. http://dx.doi.org/10.1007/bf00930023 